\title{
Effect of incorporation of honey on chilled storage and sensory acceptance of probiotic Melon Manis Terengganu (Cucumis melo var inodorus cv. Manis Terengganu 1) juice
}

\author{
*Amiza, M.A. and Loo, B.Y. \\ Faculty of Fisheries and Food Science, Universiti Malaysia Terengganu. 21030 Kuala Nerus, Terengganu. \\ Malaysia
}

\author{
Article history: \\ Received: 8 April 2020 \\ Received in revised form: 8 \\ May 2020 \\ Accepted: 15 May 2020 \\ Available Online: 2 June \\ 2020
}

\section{Keywords:}

Melon Manis Terengganu, Juice,

Probiotic,

Honey,

Sensory

\section{DOI:}

https://doi.org/10.26656/fr.2017.4(5).152

\begin{abstract}
The objective of this study was to determine the effect of 28 days of chilled storage $\left(4^{\circ} \mathrm{C}\right)$ on Melon Manis Terengganu (MMT) juice, probiotic MMT juice and probiotic MMT juice with 3.9\% honey. Furthermore, determination of sensory evaluation of these three juices using acceptance test was carried out as well. It was found that for all MMT juice samples with 28 days of chilled storage resulted in increased total soluble solid, decreased viscosity and no significant difference in titratable acidity. Besides, the $\mathrm{pH}$ of control MMT juice did not change, but the $\mathrm{pH}$ of both probiotic MMT juices decreased. It was found that there was no yeast and mould growth in probiotic MMT juice with 3.9\% honey until the $28^{\text {th }}$-day storage. However, yeast and mould growth appeared after 21 days of chilled storage for both control MMT juice and probiotic MMT juice, with control MMT juice having the higher yeast and mould count. During chilled storage, there was no LAB count and no significant change in biomass in control MMT juice, but there was a decreasing trend for LAB count and biomass for probiotic MMT juice after 21 days of storage. However, for probiotic MMT juice with honey, LAB count did not change significantly, while its biomass was higher than probiotic MMT juice after 14 days of chilled storage. Sensory evaluation found that there was no significant difference $(p<0.05)$ in acceptability of all MMT juice samples for sourness, overall acceptability and odour attributes. For colour attribute, probiotic MMT juice gave similar colour attribute acceptance with other samples. However, both probiotic juices gave lower acceptability scores for flavour and sweetness attributes compared to control MMT juice. This study found that the most acceptable formulation was control MMT juice, followed by MMT probiotic juice and finally MMT probiotic juice with 3.9\% honey.
\end{abstract}

\section{Introduction}

Fruit juice is a natural liquid contained in ripe fruits and rich in beneficial nutrients such as sugar, vitamins, minerals, fibre, and antioxidants. Thus, fruit juice is suitable substrates for the probiotic bacteria cultivation. Many researchers have been investigated the suitability of various fruit and vegetable juices as raw material for the production of probiotic juices such as tomato, mango, orange, apple, grape, peach, pomegranate and watermelon (Patel, 2017). Furthermore, fruit juices are highly prone to deterioration and the short shelf life of the fresh juices usually are caused by enzymatic, microbial, and chemical factors (Ephrem et al., 2018). According to Lebaka et al. (2018), the physicochemical and sensory qualities, especially flavour and nutritional components can be modified by fermentation.
Probiotics are defined as microorganisms that have a positive effect on the intestinal of the host by balancing the intestinal flora (Fuller, 1989). The minimum requirement for the number of probiotics bacteria present in the beverages is $10^{7} \mathrm{CFU} / \mathrm{g}$ during consumption time (Angiolillo et al., 2014). The health advantage of probiotics chiefly depends upon their concentration in foods and on their ability to endure the unfavourable conditions of the gastrointestinal tract. The major parameters influencing the number of probiotics are intrinsic food parameters such as titratable acidity, $\mathrm{pH}$, sugar, molecular oxygen and water activity. Incubation temperature, storage techniques, kind of probiotics strains and inoculums proportion also influence the growth of probiotics bacteria (Tripathi and Giri, 2014). Among the most commonly employed probiotics are Lactobacillus acidophilus, L. helveticus, L. casei, L. 
paracasei, L. johnsonii, L. plantarum, B. bifidum and B. longum (Nagpal et al., 2012; Patel, 2017). The non-dairy probiotic foods market is projected to have an annual growth rate of $15 \%$ between 2013 and 2018 (Ephrem et al., 2018). Martins et al. (2013) found that fruits, such as apple, guava, banana, and melon, have potential as carriers for probiotics bacteria.

Honey is a natural sweetener that can act as potential prebiotic because it contains many oligosaccharides and low molecular weight polysaccharides which are neither hydrolysed by host enzymes or absorbed in the upper part of the gastrointestinal tract (Hirschberg et al., 2006). It can remain available as a nutrient source for the intestinal microflora thereby acknowledged as a prebiotic material (Jan Mei et al., 2010). Sanz et al. (2005) reported honey oligosaccharides to provide potential prebiotic activity by increasing the populations of faecal bifidobacteria and lactobacilli. Most of the honey incorporated beverages were reported in the dairy product. Besides that, the natural present of Lactobacillus species in the honey can help to inhibit the growth of pathogens and bring advantageous properties for honey (Forsgren et al., 2010). In addition, the antibacterial components found in honey can enhance the probiotic efficacy against pathogens (Mohan et al., 2017). Machado et al. (2017) and Nath et al. (2015) found that the overall acceptability of honey incorporated probiotic beverages was greater than those without added honey.

Melon Manis Terengganu (Cucumis melo var inodorus cv. Manis Terengganu 1) is one of the melon species under Cantaloupe family. It has a smooth yellowgolden without netted beige of skin and together with crunchy orange coloured flesh (Muhamad et al., 2018). Fresh melon juice contains considerable amounts of total soluble solids, total sugars, reducing sugars, ascorbic acid, minerals, and free amino acids. Development of value-added products from MMT is needed because sometimes there is an oversupply of MMT fruit and rejected MMT fruit which is not suitable to be sold as whole fruit. This will help to reduce waste and generate value-added products from MMT industry. MMT juice is one of the products that can be developed from MMT. To date, no study has been reported on the effect of honey and probiotics bacteria on the changes during chilled storage and its sensory acceptance. This MMT juice also may offer alternative non-dairy probiotic juice to lactose-intolerant consumers. Thus, the objective of this study was to determine the effect of chilled storage on lactic acid bacteria (LAB) growth and physical properties of MMT juice (control), probiotic MMT juice without honey and probiotic MMT juice with 3.9\% honey as well as to determine the sensory acceptance of these three juices.

\section{Materials and methods}

\subsection{Raw materials}

A total of $20 \mathrm{~kg}$ Melon Manis Terengganu and $1 \mathrm{~kg}$ of Tualang honey were purchased from a supplier in Gong Badak, Terengganu. Melon Manis Terengganu was stored in the freezer at $-20^{\circ} \mathrm{C}$ for further used. All other chemical reagents used were of analytical grades.

\subsection{Sample preparation}

The whole fresh MMT fruits were peeled and deseeded and the flesh was cut into small pieces. After that, it was blended into juice by using a blender (Pensonic, Malaysia). The juice was then stored in $-20^{\circ} \mathrm{C}$ for further use.

\subsection{Inoculum preparation}

Pure culture of Lactobacillus plantarum was cultured in a $250 \mathrm{~mL}$ Erlenmeyer flask containing 100 $\mathrm{mL}$ of MRS broth for $24 \mathrm{hrs}$ at $37^{\circ} \mathrm{C}$ (Puertollano et al., 2009). The culture was transferred into $50 \mathrm{~mL}$ centrifuge tubes and centrifuged at $10000 \mathrm{rpm}$ for $10 \mathrm{mins}$ at $4^{\circ} \mathrm{C}$ (Ricci et al., 2019). The supernatant produced was discarded. The pellet was washed with phosphate buffer saline (PBS) ( $\mathrm{pH}$ 7.3). The mixture of PBS and pellet was centrifuged once again at $10000 \mathrm{rpm}$ for 10 mins at $4^{\circ} \mathrm{C}$. The mixture was then washed again with PBS to be used as inoculum. The purity of the culture was checked by streaking on MRS agar. Single colony on MRS agar indicated pure culture. The cell density was determined spectrophotometrically at $590 \mathrm{~nm}$ (GENESYS 20 Thermospectronic, Thermo Electron Corp., USA) until it reached 0.600 that correspond to $9.00 \log \mathrm{CFU} / \mathrm{mL}$, using MacFarland scale (Pereira et al., 2011). This culture was used as a probiotic inoculum for juice fermentation.

\subsection{Effect of honey on chilled storage of probiotic MMT juice}

MMT juice was prepared by pasteurizing the thawed juice at $80^{\circ} \mathrm{C}$ for 3 mins to kill the harmful microorganisms (Kaya et al., 2015). Next, MMT juice (control) was dispensed into glass jars and stored for chilled storage study for 28 days at $4^{\circ} \mathrm{C}$.

To prepare probiotic juices, $100 \mathrm{~mL}$ of pasteurized MMT juice in Erlenmeyer flasks were inoculated with $7.00 \log \mathrm{CFU} / \mathrm{mL}$ L. plantarum $(1 \mathrm{~mL}$ of inoculum containing $9.00 \mathrm{CFU} / \mathrm{mL}$ of $L$. plantarum). This concentration was chosen based on the recommendation for probiotic foods which should have a minimum count of $7.00 \log \mathrm{CFU} / \mathrm{mL}$ for better efficacy in regulating 
beneficial effects (Vinderola and Reinheimer, 2000). Fermentation of 2 types of MMT probiotic juices (without honey and with 3.9\% honey) were carried out statically in an incubator for $24 \mathrm{hrs}$ at $\mathrm{pH} 5.5,38^{\circ} \mathrm{C}$. Then, both types of MMT probiotic juices were dispensed into glass jars and stored for chilled storage study at $4^{\circ} \mathrm{C}$ for 28 days. Each MMT juice sample was taken every 7 days interval and was subjected to determination of biomass, LAB cell count, yeast and mould count, $\mathrm{pH}$, colour, titratable acidity, viscosity, and total soluble solids.

\subsubsection{Biomass determination}

The MMT juices were diluted with distilled water (1:10). Then, the biomass was determined by optical density measured at $590 \mathrm{~nm}$ (GENESYS 20 Thermospectronic, Thermo Electron Corp., USA) (Rodrigues et al., 2003). The distilled water was used as blank. Biomass was calculated based on a calibration curve.

\subsubsection{Viable LAB counts}

To determine the viability of lactic acid bacteria (LAB), deMan, Rogosa and Sharpe (MRS) agar was used. Serial dilutions of probiotic MMT juice sample with sterile peptone water were prepared until $10^{-6}$ dilution. Then, $0.1 \mathrm{~mL}$ of the sample was plated using spread plate method. The plates were then incubated for $72 \mathrm{hrs}$ at $37^{\circ} \mathrm{C}$. Plates containing $20-350$ colonies were counted and $\mathrm{LAB}$ counts were calculated as colony forming units (CFU) per $\mathrm{mL}$ of solution. According to Vinderola and Reinheimer (2000), LAB has characteristics round white creamy colonies with diameters from 0.9 to $1.3 \mathrm{~mm}$.

\subsubsection{Yeast and mould count}

Dichloran Rose Bengal Chloramphenicol (DRBC) agar was used to determine the yeast and mould count. Serial dilutions of the sample with sterile peptone water were prepared until $10^{-3}$ dilution. Then, $0.1 \mathrm{~mL}$ of the sample was plated using a spread plate method. The plates were incubated for 5 days at $30^{\circ} \mathrm{C}$. Plates containing 20-350 colonies were counted. Yeast and mould count were stated as colony forming units (CFU) per $\mathrm{mL}$ of solution.

\subsubsection{Determination of $\mathrm{pH}$}

$\mathrm{pH}$ of the probiotic MMT juice was determined by using a $\mathrm{pH}$ meter (Eutech Instruments Pte. Ltd., Singapore).

\subsubsection{Colour analysis}

chromameter (Konica Minolta Inc., Japan). After calibration of the chromameter, the MMT juice was placed in a transparent container and its $\mathrm{L}^{*}, \mathrm{a}^{*}, \mathrm{~b}^{*}$ values were measured.

\subsubsection{Titratable acidity}

Six grams of each juice sample was weighed into a $100 \mathrm{ml}$ beaker. Then, $50 \mathrm{ml}$ of distilled water and several drops of phenolphthalein were added into each sample. Each sample was titrated with $0.1 \mathrm{~N} \mathrm{NaOH}$ to the endpoint. The volume of $\mathrm{NaOH}$ used for titration was recorded.

\subsubsection{Viscosity}

Viscosity of the juice samples was measured using a viscometer (Brookfield DV-11+, Middleboro, MA, USA). Spindle 2 was used to determine the viscosity of beverage at a speed of $100 \mathrm{rpm}$.

\subsubsection{Determination of total soluble solids}

Total soluble solids (TSS) is equal to the percentage of sugar and other soluble or dissolved solids in a solution. A digital refractometer (model MA871, Milwaukee Instruments Inc, USA) was used to determine the TSS of the samples as ${ }^{\circ}$ Brix. Distilled water was used as a blank solution.

\subsection{Sensory evaluation}

Sensory evaluation for control MMT juices, probiotic MMT juices without honey and probiotic MMT juices with 3.9\% honey were also carried out using an acceptance test. A 7-point hedonic scale ( $1=$ dislike extremely to $7=$ like extremely) were used to evaluate the acceptance of the products. The sensory attributes including the colour, odor, Melon Manis Terengganu flavour, sweetness, sourness, overall acceptability were evaluated by forty untrained panels. All the samples were served chilled. Samples were served in paper cups and were labelled with 3-digit code.

\subsection{Statistical analysis}

All data were presented as mean \pm standard deviation. Minitab 14 software (Minitab Inc., USA) was used to conduct statistical analysis for all the results obtained from analysis and sensory evaluation. One-way analysis of variance (ANOVA) was used to determine the significant difference between the juice samples as well as the storage time. Results with significant differences were further analysed by using Tukey's comparison test to determine the significant difference among the independent variables $(\mathrm{p}<0.05)$.

Colour analysis was determined using a 


\section{Results and discussion}

\subsection{Chilled storage study}

\subsubsection{Biomass}

Biomass of LAB was measured by using a spectrophotometer. As the LAB population increased, the amount of transmitted light decreased due to the increasing turbidity. Thus, the absorbance reading reflects the number of bacteria. Figure 1 shows that the effect of incorporation of honey and LAB on the biomass of MMT juice within 28 days of chilled storage time. There was a significant difference between the biomass of the control MMT juice and the probiotic MMT juice with and without honey $(p<0.05)$. For each storage time interval, control MMT juice always gave lower biomass than both probiotic MMT juices due to the presence of $\mathrm{LAB}$ in the probiotic MMT juices. There was no significant difference between the biomass for both probiotic MMT juices $(\mathrm{p}>0.05)$. The presence of biomass in the control MMT juice may be due to the presence of pomace in the fruit juice which influences the amount of transmitted light pass through the juice.

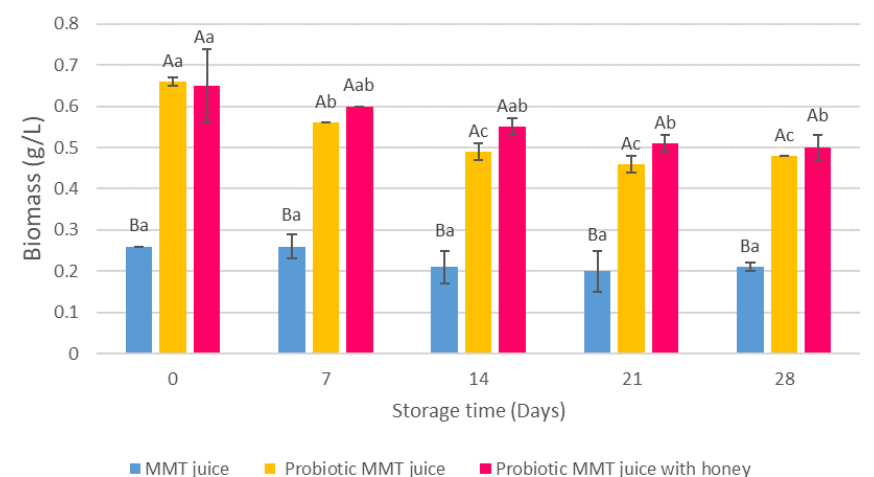

Figure 1. Effect of incorporation of honey and $\mathrm{LAB}$ on biomass of MMT juice within 28 days of chilled storage time. Bars with different uppercase letters indicate significant difference $(p<0.05)$ between sample within the same storage day while bars with different lowercase letters indicate significant difference $(\mathrm{p}<0.05)$ between storage days within same sample.

During the 28 days of chilled storage, as expected, there was no significant difference $(p>0.05)$ in the biomass of the control MMT juice. On the other hand, both probiotic MMT juice with and without honey showed a significant decrease $(\mathrm{p}<0.05)$ in biomass. This may be due to the decrease in the number of $L A B$ because of the sugar content in the MMT juice was unable to support the growth of the LAB. The reduction of the number of LAB caused the reduction of biomass. However, Pereira et al. (2011) reported a different finding whereby there was an increase in the biomass of the probiotic cashew apple juice fermented by L. casei, but it was not followed by the decrease in viability of probiotic cells. They reported that these results indicated that some cells lost their viability at the end of storage although biomass in the juice remained high.

\subsubsection{LAB count}

LAB count is important to determine the amount of probiotic strain present in the fermented drinks. A probiotic drink should contain at least $6-7 \log \mathrm{CFU} / \mathrm{g}$ or $\mathrm{mL}$ of viable probiotic bacteria at the time of ingestion to promote health benefits to the consumers (Vinderola et al., 2000). Figure 2 shows the effect of incorporation of honey and LAB on LAB cell count of MMT juice within 28 days of chilled storage time. As expected, there was no LAB growth found in the control MMT juice throughout the 28 days chilled storage. It was found that there was no significant difference in LAB count of both probiotic MMT juices on 0,7 th and 14 th day $(p>0.05)$. However, a significant decrease was found in LAB count on $21^{\text {st }}$ and $28^{\text {th }}$ day of storage. The LAB count of probiotic MMT juice without honey dropped from 7.58 $\log \mathrm{CFU} / \mathrm{mL}$ to $6.77 \log \mathrm{CFU} / \mathrm{mL}$ at the $21^{\text {st }}$ day and decreased further to $5.88 \log \mathrm{CFU} / \mathrm{mL}$ at the end of the chilled storage time. This may be due to the insufficient sugar content in MMT juice to support LAB growth.

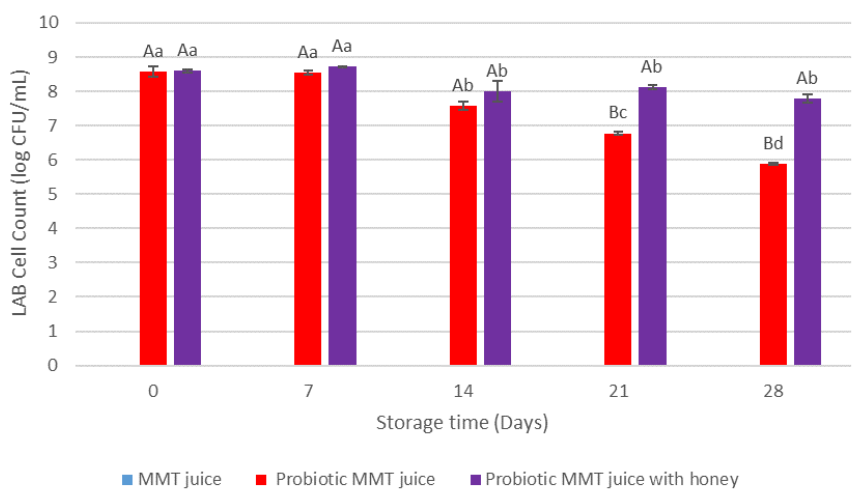

Figure 2. Effect of incorporation of honey and LAB on LAB cell count of MMT juice within 28 days of chilled storage time. Bars with different uppercase letters indicate significant difference $(\mathrm{p}<0.05)$ between sample within the same storage day while bars with different lowercase letters indicate significant difference $(\mathrm{p}<0.05)$ between storage days within same sample.

It was also noted that probiotic MMT juice with honey gave higher LAB count than that of without honey on day-21 and onwards. Honey contains a variety of oligosaccharides varying in degree of polymerization which can enhance the growth, activity and viability of lactobacilli and bifidobacteria fermented dairy and nondairy products (Slačanac et al., 2011). The natural presence of Lactobacillus species in the honey can also enhance the number of probiotic in MMT juice (Forsgren et al., 2010). Jan Mei et al. (2010) also reported that the addition of stingless bee honey in yoghurts appeared to assure the maintenance of higher counts in comparison to 
the formulation without added honey over time.

For the same juice sample during 28 days of chilled storage, LAB count of probiotic MMT juice without honey decreased gradually after day-14 onwards. LAB count of probiotic MMT juice with honey also decreased after day-14. However, the LAB count in probiotic MMT juice with honey remained constant until the end of storage $(7.78 \log \mathrm{CFU} / \mathrm{mL})$. This finding indicates that the carbohydrate content in the MMT juice was not enough to support the growth of the LAB.

This result was different to the finding of Pereira et al. (2012) who reported that the viable LAB count of probiotic cashew apple juice increased from $8.31 \mathrm{log}$ $\mathrm{CFU} / \mathrm{mL}$ to $8.63 \log \mathrm{CFU} / \mathrm{ml}$ at the end of $28^{\text {th }}$ day of storage at $4^{\circ} \mathrm{C}$. Riazi and Ziar (2012) also observed the protective effect of honey on the cell viability of LAB in fermented skim milk during 28 days of refrigerated storage.

\subsubsection{Yeast and mould count}

Yeast and mould count is important to detect and quantify the amount of fungal growth on food as well as allow for the identification of viable yeast and mould species present. Figure 3 shows the effect of incorporation of honey and LAB on yeast and mould count of MMT juice within 28 days of chilled storage time. For the first 14 days of chilled storage, all samples did not show any growth of yeast and mould. On day-21 onwards, control juice gave higher yeast and mould count than probiotic MMT juice without honey $(\mathrm{p}<0.05)$. Probiotic MMT juice with honey showed no growth of yeast and mould throughout 28 days chilled storage. This may be due to high LAB count of $7.78 \log \mathrm{CFU} / \mathrm{mL}$ at the end of storage, and the $\mathrm{LAB}$ presence can help to inhibit the growth of the yeast and mould.

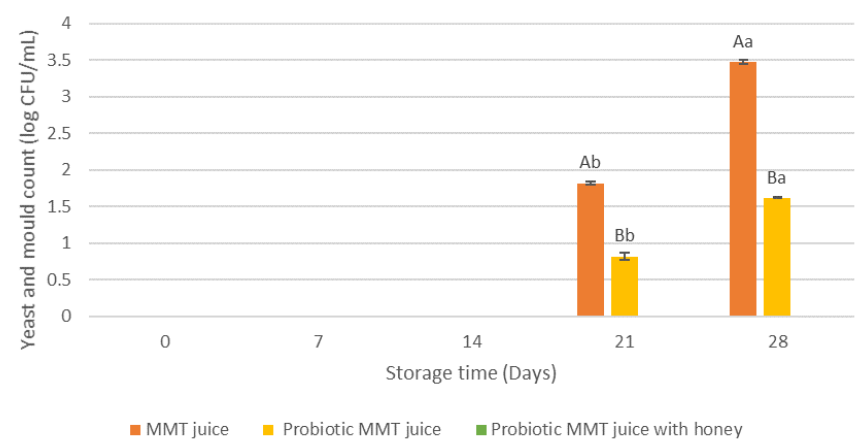

Figure 3. Effect of incorporation of honey and LAB on yeast and mould count of MMT juice within 28 days of chilled storage time. Bars with different uppercase letters indicate significant difference $(p<0.05)$ between sample within the same storage day while bars with different lowercase letters indicate significant difference $(\mathrm{p}<0.05)$ between storage days within same sample.

One of the functional requirements of $\mathrm{LAB}$ is its antagonistic activity against pathogens. The mechanisms of probiotic to protect food against pathogen include lowering of $\mathrm{pH}$, antagonism by producing bacteriocins which can kill pathogens and compete with pathogens for binding sites and receptors sites, nutrients and growth factors (Kosgey et al., 2019). Bazukyan et al. (2018) also found the antifungal activity of lactobacilli isolated from Armenian dairy products, whereby the LAB produce bacteriocin-like compounds, organic acids can inhibit the growth of mould and thereby preventing aflatoxin B1 production.

There was a significant difference in yeast and mould count of control MMT juice sample and probiotic MMT juice without honey from $21^{\text {st }}$ day onwards $(p<0.05)$. For control MMT juice, yeast and mould count was $1.82 \log \mathrm{CFU} /$ (on day-21) and increased to $3.48 \log$ $\mathrm{CFU} / \mathrm{mL}$ at end of the day of chilled storage. Yeasts and moulds often use fruit juice as substrate and cause its spoilage by producing off-flavours, off-odours and discolouration (Tournas et al., 2006). Tarazona-Díaz et al. (2017) reported that the yeast and mould count of pasteurised watermelon $\left(80^{\circ} \mathrm{C}, 90 \mathrm{~s}\right)$ was above $3.00 \mathrm{log}$ $\mathrm{CFU} / \mathrm{mL}$ on day- 15 of chilled storage. For the probiotic MMT juice without honey, it was less than $1 \log$ CFU/ $\mathrm{mL}$ initially and increased to $1.62 \log \mathrm{CFU} / \mathrm{mL}$ at the end of chilled storage. The increase of yeast and mould count may be due to low $\mathrm{pH}$ condition was suitable for yeast and mould growth and the reduction of probiotic microorganisms resulted in the reduction of antifungal effect. According to the USDA (2001), yeast and mould count should not more than 50 per ml. Thus, both probiotic MMT juices were still safe after 28 days of chilled storage. For control MMT juice, its yeast and mould count exceed the USDA limit on day-21 onwards.

\subsection{4 pH analysis}

$\mathrm{pH}$ is an important factor that affects the viability of LAB and sensory attribute of the probiotic fruit juice. Figure 4 shows the effect of incorporation of honey and LAB on $\mathrm{pH}$ of MMT juice within 28 days of chilled storage time. There was a significant difference in $\mathrm{pH}$ between control MMT juice and both probiotic MMT juices $(\mathrm{p}<0.05)$. The $\mathrm{pHs}$ of both probiotic MMT juices were lower than that of control MMT juice. This was due to the presence of LAB which utilized the sugar present in the juice and caused accumulation of lactic acid. There was no difference in $\mathrm{pH}$ between both probiotic MMT juices except on day-21 and day-28. Probiotic MMT juice with honey on day- 28 gave lower $\mathrm{pH}$ probably due to the addition of honey may cause a slight reduction of the initial $\mathrm{pH}$. The acidity of honey came from naturally occurring organic acids in its composition (Chuttong et al., 2016). 


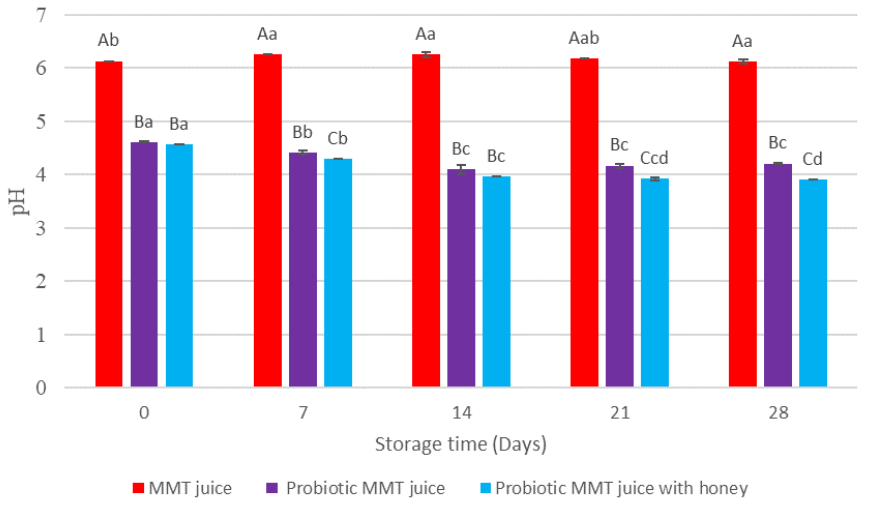

Figure 4. Effect of incorporation of honey and LAB on $\mathrm{pH}$ of MMT juice within 28 days of storage. Bars with different uppercase letters indicate significant difference $(p<0.05)$ between sample within the same storage day while bars with different lowercase letters indicate significant difference $(p<0.05)$ between storage days within same sample.

The $\mathrm{pH}$ of control MMT juice did not change significantly during the 28 days of chilled storage. However, the $\mathrm{pH}$ of both probiotic MMT juices showed a significant decrease after 7 days of chilled storage. This is due to the fermentation of the glucose into lactic acid by the LAB. The $\mathrm{pH}$ range of probiotic MMT juice with and without honey obtained in this study were 4.03-4.62 and 3.89-4.57, respectively.

Pereira et al. (2011) reported a similar trend whereby the $\mathrm{pH}$ values of probiotic cashew apple reduced from 4.28 to 3.79 after 42 days of refrigerated storage. Guo et al. (2009) reported that the L. casei reduced the $\mathrm{pH}$ of fermented milk from 5.59 to 4.60 after 28 days of chilled storage. Akalin et al. (2004) also reported a similar trend for yoghurts whereby the $\mathrm{pH}$ decreased from 4.51 to 4.40 after 28 days of refrigerated storage at $4{ }^{\circ} \mathrm{C}$. The probiotic strain used and whether the products were based on milk or water influence the $\mathrm{pH}$ levels of the probiotic products. Water-based products obtained significantly lower $\mathrm{pH}$ levels and faster reduction in $\mathrm{pH}$ during storage (Ranadheera et al., 2010). Machado et al. (2017) reported that the $\mathrm{pH}$ of the yoghurt added with different concentration of stingless bee honey continuously decreased until the $28^{\text {th }}$ day of storage. The $\mathrm{pH}$ of yoghurt samples containing 5\%,10\%, $15 \%$ of honey was decreased from 4.57 to $4.31,4.51$ to 4.27 , and 4.48 to 4.21 , respectively.

\subsubsection{Colour analysis}

Colour is the most important product-intrinsic sensory cue when it comes to setting consumers' expectations regarding the likely taste and flavour of food and drink. Colour deterioration can be caused by changes in physical, chemical or microbiological parameters in food (Coggins et al., 2010). Chroma meter determines the colour of samples based on $\mathrm{L}^{*} \mathrm{a} * \mathrm{~b} *$ colour system whereby $\mathrm{L}^{*}$ value represents lightness ( $\mathrm{L}^{*}$ $=0$ indicates black while $\mathrm{L}^{*}=100$ indicates white), $\mathrm{a}^{*}$ value represents redness (positive a) and greenness (negative a) while $b^{*}$ represents yellowness (positive $b$ ) and blueness (negative $b$ ). Table 1 shows the effect of incorporation of honey and LAB on lightness $\left(\mathrm{L}^{*}\right)$, red/ greenness $\left(\mathrm{a}^{*}\right)$ and yellow/blue $\left(\mathrm{b}^{*}\right)$ of MMT juice within 28 days of chilled storage. One-way ANOVA test showed that there was no significant difference in the lightness of all juice samples on $1^{\text {st }}$ and $7^{\text {th }}$ day $(p>0.05)$. After $14^{\text {th }}$ day, it is noted that there was a significant difference between the lightness of control juice and both probiotic MMT juice samples $(\mathrm{p}<0.05)$. The lightness of both probiotic MMT juices was lower than that of the control MMT juice probably due to higher turbidity caused by the biomass given by L. plantarum. A similar finding has been reported in probiotic cashew apple juice as reported by Pereira et al. (2011).

There was no significant difference in the a* values (redness) of control and probiotic MMT juice with and without honey $(p>0.05)$. Whereas the $b^{*}$ values of the

Table 1. Effect of incorporation of honey and LAB on lightness $\left(\mathrm{L}^{*}\right)$, red/greenness $\left(\mathrm{a}^{*}\right)$ and yellow/blue $\left(\mathrm{b}^{*}\right)$ of MMT juice within 28 days of chilled storage

\begin{tabular}{|c|c|c|c|c|c|c|c|c|c|}
\hline \multirow{3}{*}{$\begin{array}{c}\text { Storage } \\
\text { days }\end{array}$} & \multicolumn{9}{|c|}{ Samples } \\
\hline & \multicolumn{3}{|c|}{ Control } & \multicolumn{3}{|c|}{ Probiotic MMT juice } & \multicolumn{3}{|c|}{ Probiotic MMT juice with honey } \\
\hline & $\mathrm{L}^{*}$ value & $a^{*}$ value & $\mathrm{b}^{*}$ value & $\mathrm{L}^{*}$ value & $a^{*}$ value & $\mathrm{b}^{*}$ value & $\mathrm{L}^{*}$ value & $a^{*}$ value & $\mathrm{b}^{*}$ value \\
\hline 1 & $\begin{array}{l}11.23 \pm \\
0.90^{\mathrm{Ad}}\end{array}$ & $\begin{array}{l}1.13 \pm \\
0.00^{\mathrm{Aa}}\end{array}$ & $\begin{array}{l}5.31 \pm \\
0.28^{\mathrm{Ab}}\end{array}$ & $\begin{array}{l}7.23 \pm \\
2.26^{\mathrm{Ab}}\end{array}$ & $\begin{array}{l}1.31 \pm \\
0.06^{\mathrm{Aa}}\end{array}$ & $\begin{array}{c}3.98 \pm \\
1.44^{\mathrm{Ab}}\end{array}$ & $\begin{array}{l}9.37 \pm \\
0.64^{\mathrm{Ad}}\end{array}$ & $\begin{array}{c}1.21 \pm \\
0.11^{\mathrm{Aa}}\end{array}$ & $\begin{array}{l}5.22 \pm \\
0.35^{\mathrm{Ab}}\end{array}$ \\
\hline 7 & $\begin{array}{c}15.32 \pm \\
1.12^{\mathrm{Ac}}\end{array}$ & $\begin{array}{c}0.90 \pm \\
0.00^{\mathrm{Ab}}\end{array}$ & $\begin{array}{l}5.90 \pm \\
0.48^{\mathrm{Ab}}\end{array}$ & $\begin{array}{l}15.18 \pm \\
0.68^{\mathrm{Aa}}\end{array}$ & $\begin{array}{c}0.96 \pm \\
0.03^{\mathrm{Aab}}\end{array}$ & $\begin{array}{c}4.71 \pm \\
0.11^{\text {Bab }}\end{array}$ & $\begin{array}{c}14.66 \pm \\
0.16^{\mathrm{Ac}}\end{array}$ & $\begin{array}{c}0.94 \pm \\
0.01^{\mathrm{Ab}}\end{array}$ & $\begin{array}{c}5.07 \pm \\
0.10^{\mathrm{ABb}}\end{array}$ \\
\hline 14 & $\begin{array}{c}20.90 \pm \\
0.11^{\mathrm{Aa}}\end{array}$ & $\begin{array}{l}0.58 \pm \\
0.03^{\mathrm{Ad}}\end{array}$ & $\begin{array}{c}6.57 \pm \\
0.63^{\mathrm{Aab}}\end{array}$ & $\begin{array}{c}16.60 \pm \\
0.61^{\mathrm{Ba}}\end{array}$ & $\begin{array}{c}0.75 \pm \\
0.28^{\mathrm{Ab}}\end{array}$ & $\begin{array}{c}5.53 \pm \\
0.05^{\text {Aab }}\end{array}$ & $\begin{array}{c}20.37 \pm \\
0.69^{\mathrm{Aa}}\end{array}$ & $\begin{array}{c}0.40 \pm \\
0.16^{\mathrm{Ac}}\end{array}$ & $\begin{array}{l}6.16 \pm \\
0.29^{\mathrm{Aa}}\end{array}$ \\
\hline 21 & $\begin{array}{c}18.48 \pm \\
0.25^{\mathrm{Ab}}\end{array}$ & $\begin{array}{l}0.71 \pm \\
0.11^{\mathrm{Ac}}\end{array}$ & $\begin{array}{l}7.15 \pm \\
0.29^{\mathrm{Aa}}\end{array}$ & $\begin{array}{c}15.28 \pm \\
0.86^{\mathrm{Ba}}\end{array}$ & $\begin{array}{l}0.64 \pm \\
0.05^{\mathrm{Ab}}\end{array}$ & $\begin{array}{c}5.77 \pm \\
0.37^{\mathrm{Bab}}\end{array}$ & $\begin{array}{l}16.80 \pm \\
0.17^{\mathrm{ABb}}\end{array}$ & $\begin{array}{c}0.53 \pm \\
0.00^{\mathrm{Ac}}\end{array}$ & $\begin{array}{c}6.39 \pm \\
0.06^{\mathrm{ABa}}\end{array}$ \\
\hline 28 & $\begin{array}{l}19.04 \pm \\
0.29^{\mathrm{Aab}} \\
\end{array}$ & $\begin{array}{l}0.54 \pm \\
0.04^{\mathrm{Ad}}\end{array}$ & $\begin{array}{l}7.23 \pm \\
0.24^{\mathrm{Aa}} \\
\end{array}$ & $\begin{array}{l}17.2 \pm \\
0.00^{\mathrm{Ba}}\end{array}$ & $\begin{array}{l}0.46 \pm \\
0.00^{\mathrm{Ab}}\end{array}$ & $\begin{array}{l}5.77 \pm \\
0.00^{\mathrm{Ba}} \\
\end{array}$ & $\begin{array}{c}17.26 \pm \\
0.29^{\mathrm{Bb}} \\
\end{array}$ & $\begin{array}{l}0.47 \pm \\
0.03^{\mathrm{Ac}} \\
\end{array}$ & $\begin{array}{l}5.87 \pm \\
0.08^{\mathrm{Ba}} \\
\end{array}$ \\
\hline
\end{tabular}

Values are expressed as mean \pm standard deviation. Values with different uppercase superscript within the same row are significantly different $(\mathrm{p}<0.05)$ while values with different lowercase superscripts within the same column are significantly different $(\mathrm{p}<0.05)$. 
control MMT juice was highest compared to both probiotic MMT juices. This could be due to degradation of carotenoids by LAB or fermentation conditions such as temperature and $\mathrm{pH}$ (Panda et al., 2007). The colour component $\mathrm{b}^{*}$ of the probiotic MMT juice with honey was higher than without honey. This may be due to the addition of the honey causing increase in yellowness of the MMT juice.

\subsubsection{Titratable acidity}

Figure 5 shows the effect of incorporation of honey and LAB on titratable acidity of MMT juice within 28 days of chilled storage. There was a significant difference $(p<0.05)$ in titratable acidity between control MMT juice and both probiotic MMT juices. Both probiotic MMT juices gave higher titratable acidity than control MMT juice. According to Pereira et al. (2012), the titratable acidity of the probiotic fruit juice increases due to the conversion of sugar into lactic acid by LAB. The titratable acidity of probiotic MMT juice with honey was higher than that without honey because it contained extra sugar from the addition of honey, leading to more sugar can be converted by LAB to lactic acid. Moreover, higher acidity in probiotic MMT juice containing honey may also be associated with the presence of prebiotic oligosaccharides in stingless bee honey because these compounds at such a small amount may promote the growth and/or the metabolic activity of LAB.

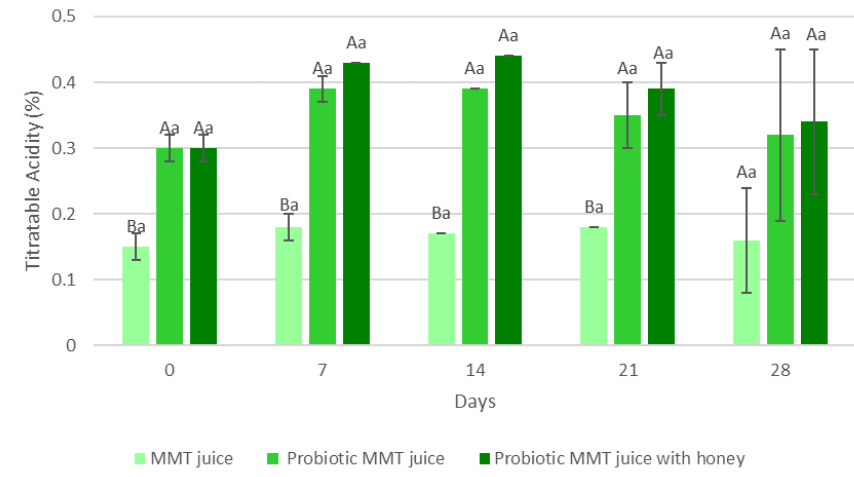

Figure 5. Effect of incorporation of honey and LAB on titratable acidity of MMT juice within 28 days of storage. Bars with different uppercase letters indicate significant difference $(\mathrm{p}<0.05)$ between sample within the same storage day while bars with different lowercase letters indicate significant difference $(p<0.05)$ between storage days within same sample.

Throughout the 28 days of chilled storage period, all samples showed no significant changes in titratable acidity. This is expected because LAB count decreased with storage time, thus there was no increase in lactic acid with storage time. Contrasting results were reported by Nualkaekul et al. (2001) whereby lactic acid levels increased in orange, grapefruit, blackcurrant, and pineapple juices fermented with Bifidobacterium longum NCIMB 8809. Mahmood et al. (2019) also reported that the titratable acidity of probiotic yoghurt prepared with Dahi micro-flora improved steadily during the 28 days of storage.

\subsubsection{Viscosity}

Viscosity is an important characteristic to determine in the food industry because it is a good indicator of density and related to the appearance of the product (Thakur, 2017). Figure 6 shows the effect of incorporation of honey and $\mathrm{LAB}$ on the viscosity of MMT juice within 28 days of storage. On a similar storage day, there was no significant difference $(p>0.05)$ in viscosity in all juice samples within 28 days storage except on the $7^{\text {th }}$ day. On the $7^{\text {th }}$ day, the viscosity of probiotic MMT juice without honey showed the lowest viscosity $(3.15 \mathrm{cP})$. This can be explained the utilization of sugar in MMT juice by probiotic microorganisms caused the decreased in the viscosity. According to Gangwar et al. (2018), the viscosity of the food can be influenced by the sugar content. An increase in the soluble solids can enhance the flow resistance that leads to an increase in viscosity of the liquid. Honey contains high sugar content which can increase the viscosity of the probiotic MMT juice and this caused its viscosity higher than probiotic MMT juice without honey.

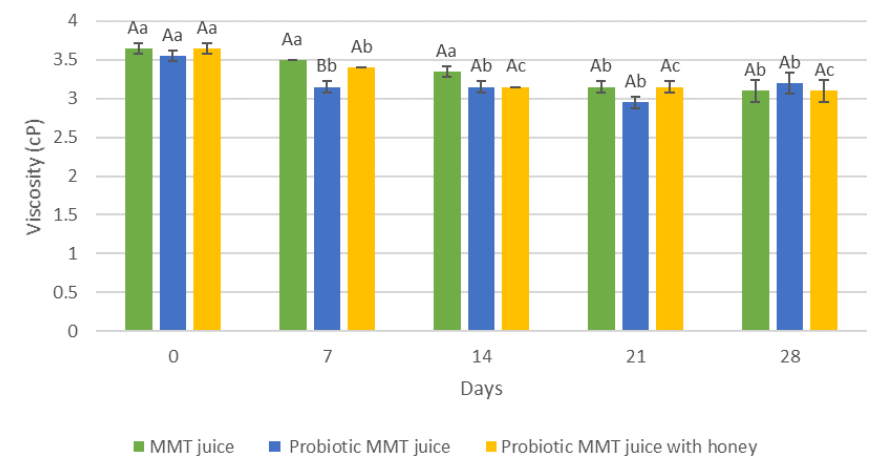

Figure 6: Effect of incorporation of honey and LAB on viscosity of MMT juice within 28 days of storage. Bars with different uppercase letters indicate significant difference $(p<0.05)$ between sample within the same storage day while bars with different lowercase letters indicate significant difference $(\mathrm{p}<0.05)$ between storage days within same sample.

Throughout 28 days of chilled storage, there was a significant decrease in viscosity after day- 21 for control MMT juice $(p<0.05)$. For probiotic MMT juice with and without honey, there was a significant decrease $(p<0.05)$ in viscosity after day-7. The loss of viscosity in control MMT juice may be related to the depolymerization of pectin due to endogenous pectinase action (pectin methylesterase (PME) and polygalacturonase (PG) during storage (Aguiló-Aguayo et al., 2010). Besides that, the viscosity of MMT probiotic juice with and 
without honey also decreased during 28 days of storage due to the utilization of sugar by LAB. Similar finding has been reported by Mahmood et al. (2019) and Donkor et al. (2007) for probiotic yoghurt. Aryana and McGrew (2007) findings also observed a gradual reduction in the apparent viscosity of probiotic yoghurt possibly due to the activity of bacteria enzymes on the matrix of casein micelles over time.

A different finding was reported by Da Costa et al. (2017) who reported that there was no difference in the viscosity of the probiotic orange juice within 28 days chilled storage. The viscosity of juice also may be influenced by types and concentration of culture bacteria (Aryana and McGrew, 2007) ).

\subsubsection{Total soluble solids (TSS)}

Figure 7 shows the effect of incorporation of honey and LAB on TSS of MMT juice within 28 days of storage. One-way ANOVA test showed that there was a significant difference $(\mathrm{p}<0.05)$ between the TSS of control MMT juice, probiotic MMT juice with and without honey on day 0 . The initial TSS of probiotic MMT juice with honey was the highest which was $7.55^{\circ}$ Brix compared to control MMT juice and probiotic MMT juice without honey which was $3.6^{\circ} \mathrm{Brix}$ and $4.85^{\circ}$ Brix respectively. An increase in TSS content of the probiotic MMT juice was due to the increase in viable cell counts after fermentation (Gangwar et al., 2018). With the increasing storage period, the TSS of control MMT juice increased. The increase is probably due to the hydrolysis of polysaccharides like starch, cellulose, pectin, etc. and conversion into simple sugars (MgayaKilima et al., 2014). On day 7 and 14, control MMT juice gave lower TSS compared to both probiotic juices. Whereas on day 21 and 28, there was no significant difference in TSS of all MMT juice samples.

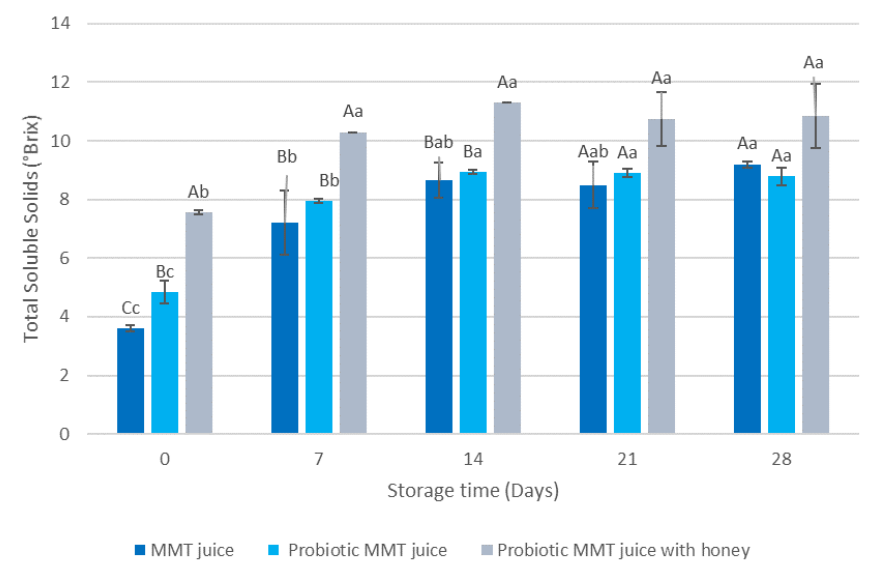

Figure 7. Effect of incorporation of honey and LAB on total soluble solid of MMT juice within 28 days of storage. Bars with different uppercase letters indicate significant difference $(p<0.05)$ between sample within the same storage day while bars with different lowercase letters indicate significant difference $(p<0.05)$ between storage days within same sample.
One-way ANOVA test showed that there was a significant difference in TSS for all MMT juice samples with increasing storage period $(\mathrm{p}<0.05)$. The TSS of control MMT juice and probiotic MMT juice increased and kept almost constant after the $14^{\text {th }}$ day until the end of storage period. For the probiotic MMT juice with honey, TSS increased from day- 0 to day- 7 and then maintained its TSS until the end of storage period. The action of enzymes that catalyse the bee enzyme transfer D-glucopyranosyl sucrose to a carbohydrate receptor caused the increase in sugar content in honey samples (Machado et al., 2017). In addition, greater amounts of reducing sugars were released to probiotic MMT juice due to certain microbial enzymes action toward honey sugars (Machado et al., 2017). Additional free sugar molecules from honey in this matrix may release due to the action of enzymes produced by LAB. These new available sugar molecules may increase the total sugars content.

Similar findings were reported by Nath et al. (2015) for honey probiotic beverage, whereby TSS increased after 15 days of chilled storage $\left(24^{\circ}\right.$ Brix to $31^{\circ}$ Brix $)$. Machado et al. (2017) also reported that the increase in total sugar content was observed at the end of the assessed storage period for all yoghurt formulations, but this increase was more evident in formulations yoghurt with $10 \%$ and $15 \%$ of honey concentration on the $14^{\text {th }}$ or $21^{\text {st }}$ day of storage. However, a reduction of TSS in probiotic pineapple juice samples during storage was observed by Tayo and Akpeji (2016). They reported that the reduction of TSS was due to the metabolic activity of the probiotic LAB. Kumar et al. (2013) also reported a reduction of TSS in fruit juice with $L$. casei.

\subsection{Sensory acceptance}

The sensory evaluation was conducted by 40 untrained panellists. Sensory attributes such as colour, odour, MMT flavour, sweetness, sourness and overall acceptability were evaluated in control MMT juice, probiotic MMT juice with and without honey. Table 2 shows that the sensory acceptance of MMT juice, probiotic MMT juice with and without honey for various attributes.

There was no significant difference $(\mathrm{p}<0.05)$ in all three formulations MMT juice samples for sourness, overall acceptability and odour attributes. This indicates that all three juice samples have similar acceptability for these three attributes. For other attributes, there was a significant difference between the three MMT juice samples. For colour attribute, control MMT juice gave a higher score compared to probiotic MMT juice with honey $(p<0.05)$. However, the colour acceptability of probiotic MMT juice without honey was not 
Table 2. Sensory acceptance of control MMT juice, probiotic MMT juice without honey and probiotic MMT juice with 3.9\% honey

\begin{tabular}{lcccccc}
\hline Sample & Colour & Odour & MMT flavour & Sweetness & Sourness & Overall Acceptability \\
\hline Control MMT juice & $6.3 \pm 0.91^{\mathrm{a}}$ & $5.2 \pm 1.45^{\mathrm{a}}$ & $5.58 \pm 1.57^{\mathrm{a}}$ & $5.23 \pm 1.64^{\mathrm{a}}$ & $4.95 \pm 1.6^{\mathrm{a}}$ & $5.1 \pm 1.77^{\mathrm{a}}$ \\
Probiotic MMT juice without honey & $5.95 \pm 0.78^{\mathrm{ab}}$ & $4.58 \pm 1.55^{\mathrm{a}}$ & $4.58 \pm 1.58^{\mathrm{b}}$ & $4.33 \pm 1.4^{\mathrm{b}}$ & $4.2 \pm 1.74^{\mathrm{a}}$ & $4.65 \pm 1.56^{\mathrm{a}}$ \\
Probiotic MMT juice with 3.9\% honey & $5.69 \pm 0.95^{\mathrm{b}}$ & $4.31 \pm 1.32^{\mathrm{a}}$ & $4.28 \pm 1.56^{\mathrm{b}}$ & $4.3^{\mathrm{b}} \pm 1.7^{\mathrm{b}}$ & $4.18 \pm 1.78^{\mathrm{a}}$ & $4.39 \pm 1.53^{\mathrm{a}}$ \\
\hline
\end{tabular}

Values are expressed as mean \pm standard deviation. Values with different superscripts within the same column are significantly different $(\mathrm{p}<0.05)$.

significantly different from other samples. This result is associated with the colour analysis which means higher yellowness and total colour difference of MMT juice, higher the acceptance of the panel.

For MMT flavour, control MMT juice gave a higher score than other samples. According to Cruz et al. (2010), the production of components by the metabolism of the probiotic culture can contribute negatively to the aroma and taste of the product. Luckow and Delahunty (2004) investigated that the sensory characteristics attributed to the functional orange juices included "lactic aroma, medicinal taste, artificial, and earthy taste". The authors reported that infrequent consumer did not reject the product although these attributes were completely unacceptable to frequent consumers of conventional orange juice. This result contrasted with the report by Machado et al. (2017), whereby they found that the goat yoghurt with the highest concentration of honey had the highest flavour acceptance. In this study, the result showed that the addition of probiotic microorganisms affects the sensory profile of the final product.

For the sweetness acceptance, MMT juice gave the highest mean score while probiotic MMT juice with and without honey showed no significant difference $(\mathrm{p}>0.05)$ between each other. This may be due to utilisation of sugar by the probiotic microorganisms, causing reduction of sugar in probiotic MMT juice. It was also found that the addition of $3.9 \%$ honey in probiotic MMT juice gave no effect on the sweetness of the probiotic MMT juice.

Higher acceptability score was reported when fermented milk with Bifidobacteria was added with 5$10 \%$ honey due to the presence of pleasant flavourforming compounds (Riazi and Ziar, 2012). Higher acidity observed in probiotic MMT juice with honey impact negatively on the sensory acceptance and reduce the original sweetness of the honey. This can be overcome by shortening the fermentation time of LAB to less than $24 \mathrm{hrs}$. Since the control MMT sample obtained the highest scores in most of the sensory attributes, thus, the most acceptable sample was the control MMT sample. Thus, it can be concluded that the addition of probiotic microorganisms and $3.9 \%$ honey negatively affected the sensory attributes of the MMT juice

samples.

\section{Conclusion}

For all MMT juice samples, 28 days of chilled storage resulted in increased TSS, decreased viscosity and no significant differences in titratable acidity. During chilled storage, $\mathrm{pH}$ of control MMT juice did not change, but $\mathrm{pH}$ of both probiotic MMT juices decreased. There was no yeast and mould growth in probiotic MMT juice with honey. At the 21 and 28 days of storage, control MMT juice gave higher yeast and mould count than probiotic MMT juice without honey. During chilled storage, there was no LAB count in control MMT juice, but the LAB count decreased for both probiotic MMT juices. During chilled storage, there was no significant change in biomass for control MMT juice, but the biomass decreased for both probiotic MMT juices. The most acceptable sensory formulation was the control MMT juice followed by probiotic MMT juice without honey and probiotic MMT juice with honey.

\section{Acknowledgement}

The research work was funded by Knowledge and Technology Assimilation Grant (KTAG) (Vot. No. 58901), Universiti Malaysia Terengganu to carry out this study.

\section{References}

Aguiló-Aguayo, I., Soliva-Fortuny, R. and MartínBelloso, O. (2010). Colour and viscosity of watermelon juice treated by high-intensity pulsed electric fields or heat. Innovative Food Science and Emerging Technologies, 11(2), 299-305. https:// doi.org/10.1016/j.ifset.2009.12.004

Akalin, A.S., Fenderya, S. and Akbulut, N. (2004). Viability and activity of bifidobacteria in yoghurt containing fructooligosaccharide during refrigerated storage. International Journal of Food Science and Technology, 39(6), 613-621. https://doi.org/10.1111/ j.1365-2621.2004.00829.x

Angiolillo, L., Conte, A., Faccia, M., Zambrini, A. V. and Del Nobile, M.A. (2014). A new method to produce synbiotic Fiordilatte cheese. Innovative Food Science and Emerging Technologies, 22, 180- 
187. https://doi.org/10.1016/j.ifset.2013.09.010

Aryana, K.J. and McGrew, P. (2007). Quality attributes of yoghurt with Lactobacillus casei and various prebiotics. LWT - Food Science and Technology, 40 (10), 1808-1814. https://doi.org/10.1016/ j.lwt.2007.01.008

Bazukyan, I., Matevosyan, L., Toplaghaltsyan, A. and Trchounian, A. (2018). Antifungal activity of lactobacilli isolated from Armenian dairy products: an effective strain and its probable nature. $A M B$ Express, 8, 87. https://doi.org/10.1186/s13568-0180619-y

Chuttong, B., Chanbang, Y., Sringarm, K. and Burgett, M. (2016). Physicochemical profiles of stingless bee (Apidae: Meliponini) honey from South East Asia (Thailand). Food Chemistry, 192, 149-155. https:// doi.org/10.1016/j.foodchem.2015.06.089

Coggins, P.C., Rowe, D.E., Wilson, J.C. and Kumari, S. (2010). Storage and temperature effects on appearance and textural characteristics of conventional milk yoghurt. Journal of Sensory Studies, 25(4), 549-576. https://doi.org/10.1111/ j.1745-459X.2010.00286.x

Cruz, A.G., Cadena, R.S., Walter, E.H.M., Mortazavian, A.M., Granato, D., Faria, J.A.F. and Bolini, H.M.A. (2010). Sensory analysis: Relevance for prebiotic, probiotic, and synbiotic product development. Comprehensive Reviews in Food Science and Food Safety, 9(4), 358-373. https://doi.org/10.1111/j.15414337.2010.00115.x

da Costa, G.M., de Carvalho Silva, J.V., Mingotti, J.D., Barão, C.E., Klososki, S.J. and Pimentel, T.C. (2017). Effect of ascorbic acid or oligofructose supplementation on $L$. paracasei viability, physicochemical characteristics and acceptance of probiotic orange juice. LWT-Food Science and Technology, 75, 195-201. https://doi.org/10.1016/ j.lwt.2016.08.051

Donkor, O.N., Henriksson, A., Singh, T.K., Vasiljevic, T. and Shah, N.P. (2007). ACE-inhibitory activity of probiotic yoghurt. International Dairy Journal, 17 (11), 1321-1331. https://doi.org/10.1016/ j.idairyj.2007.02.009

Ephrem, E., Najjar, A., Charcosset, C. and GreigeGerges, H. (2018). Encapsulation of natural active compounds, enzymes, and probiotics for fruit juice fortification, preservation, and processing, An overview. Journal of Functional Foods, 48, 65-84. https://doi.org/10.1016/j.jff.2018.06.021

Forsgren, E., Olofsson, T.C., Vásquez, A. and Fries, I. (2010). Novel lactic acid bacteria inhibiting Paenibacillus larvae in honeybee larvae. Apidologie,
41, 99-108. https://doi.org/10.1051/apido/2009065

Fuller, R. (1989). Probiotics in man and animals. Journal of Applied Bacteriology, 66(5), 365-378. https:// doi.org/10.1111/j.1365-2672.1989.tb05105.x

Gangwar, A.S., Bhardwaj, A. and Sharma, V. (2018). Fermentation of tender coconut water by probiotic bacteria Bacillus coagulans. International Journal of Food Studies, 7, 100-110. https://doi.org/10.7455/ ijfs/7.1.2018.a9

Guo, Z., Wang, J., Yan, L., Chen, W., Liu, X.M. and Zhang, H.P. (2009). In vitro comparison of probiotic properties of Lactobacillus casei Zhang, a potential new probiotic, with selected probiotic strains. $L W T$ Food Science and Technology, 42(10), 1640-1646. https://doi.org/10.1016/j.1wt.2009.05.025

Hirschberg, J., Ibdah, M., Azulay, Y., Wasserman, B., Katzir, N., Bar, E. and Portnoy, V. (2006). Functional characterization of CmCCD1, a carotenoid cleavage dioxygenase from melon. Phytochemistry, 67(15), 1579-1589. https:// doi.org/10.1016/j.phytochem.2006.02.009

Jan Mei, S., Mohd Nordin, M.S. and Norrakiah, A.S. (2010). Fructooligosaccharides in honey and effects of honey on growth of Bifidobacterium longum BB 536. International Food Research Journal, 17, 557561.

Kaya, Z., Yildiz, S. and Ünlütürk, S. (2015). Effect of UV-C irradiation and heat treatment on the shelf life stability of a lemon-melon juice blend, Multivariate statistical approach. Innovative Food Science and Emerging Technologies, 29, 230-239. https:// doi.org/10.1016/j.ifset.2015.03.005

Kosgey, J.C., Jia, L., Fang, Y., Yang, J., Gao, L., Wang, J. and Zhang, F. (2019). Probiotics as antifungal agents: Experimental confirmation and future prospects. Journal of Microbiological Methods, 162, 28-37. https://doi.org/10.1016/j.mimet.2019.05.001

Kumar, B.V., Sreedharamurthy, M. and Reddy, O.V.S. (2013). Physico-Chemical Analysis of Fresh and Fermented Fruit Juices Probioticated with Lactobacillus casei. International Journal of Applied Sciences and Biotechnology, 1, 127-131. https:// doi.org/10.3126/ijasbt.vli3.8301

Lebaka, V.R., Wee, Y.J., Narala, V.R. and Joshi, V.K. (2018). Development of New Probiotic Foods- A Case Study on Probiotic Juices. In Grumezescu, A.M. and Holban, A.M. (Eds.). Therapeutic, Probiotic, and Unconventional Foods. USA: Academic Press. https://doi.org/10.1016/B978-0-12814625-5.00004-2

Luckow, T. and Delahunty, C. (2004). Consumer acceptance of orange juice containing functional 
ingredients. Food Research International, 37(8), 805 -814. https://doi.org/10.1016/j.foodres.2004.04.003

Machado, T.A.D.G., de Oliveira, M.E.G., Campos, M.I.F., de Assis, P.O.A., de Souza, E.L., Madruga, M.S. and Queiroga, R.C.R.E. (2017). Impact of honey on quality characteristics of goat yoghurt containing probiotic Lactobacillus acidophilus. LWT - Food Science and Technology, 80, 221-229. https:// doi.org/10.1016/j.lwt.2017.02.013

Mahmood, T., Masud, T., Qayyum, A., Mehmood, A., Ahmed, W., Liaquat, M. and Ali, S. (2019). Functional and technological attributes of probiotic yoghurt prepared with Dahi micro-flora during refrigerated storage. Food Science and Technology, 39, 267-273. https://doi.org/10.1590/fst.12317

Martins, E.M.F., Ramos, A.M., Vanzela, E.S.L., Stringheta, P.C., de Oliveira Pinto, C.L. and Martins, J.M. (2013). Products of vegetable origin, A new alternative for the consumption of probiotic bacteria. Food Research International, 51(2), 764-770. https://doi.org/10.1016/j.foodres.2013.01.047

Mgaya-Kilima, B., Remberg, S.F., Chove, B.E. and Wicklund, T. (2014). Influence of storage temperature and time on the physicochemical and bioactive properties of roselle-fruit juice blends in plastic bottle. Food Science and Nutrition, 2(2), 181191. https://doi.org/10.1002/fsn3.97

Mohan, A., Quek, S.Y., Shu, Q., Gao, Y. and GutierrezMaddox, N. (2017). Effect of honey in improving the gut microbial balance. Food Quality and Safety, 1 (2), 107-115. https://doi.org/10.1093/fqsafe/fyx015

Muhamad, N., Sahadan, W. and Ho, H.L. (2018). Effect of drying temperatures and extraction solvents on total phenolic, flavonoid contents and antioxidant properties of immature Manis Terengganu Melon (Cucumis melo). Journal of Agrobiotechnology, 9 (1S), 114-121.

Nagpal, R., Kumar, A. and Kumar, M. (2012). Fortification and fermentation of fruit juices with probiotic lactobacilli. Annals of Microbiology, 62, 1573-1578. https://doi.org/10.1007/s13213-011-0412 $-5$

Nath, A.H., Ukkuru, M.P. and Kumari, M.K. (2015). Development of a probiotic honey beverage. International Journal of Applied and Pure Science and Agriculture, 1, 130-139.

Nualkaekul, S., Salmeron, I. and Charalampopoulos, D. (2001). Investigation of the factors influencing the survival of Bifidobacterium longum in model acidic solutions and fruit juices. Food Chemistry, 129(3), 1037-1044. https://doi.org/10.1016/ j.foodchem.2011.05.071
Panda, S.H., Parmanick, M. and Ray, R.C. (2007). Lactic acid fermentation of sweet potato (Ipomoea batatas L.) into pickles. Journal of Food Processing and Preservation, 31(1), 83-101. https://doi.org/10.1111/ j.1745-4549.2007.00110.x

Patel, A.R. (2017). Probiotic fruit and vegetable juicesrecent advances and future perspective. International Food Research Journal, 24(5), 1850-1857.

Pereira, A.L.F., de Jesus, A.L.T., Rodrigues, S., Almeida, F.D.L. and da Costa, J.M.C. (2012). Storage stability and acceptance of probiotic beverage from cashew apple juice. Food and Bioprocess Technology, 6, 3155-3165. https:// doi.org/10.1007/s11947-012-1032-1

Pereira, A.L.F., Maciel, T.C. and Rodrigues, S. (2011). Probiotic beverage from cashew apple juice fermented with Lactobacillus casei. Food Research International, 44(5), 1276-1283. https:// doi.org/10.1016/j.foodres.2010.11.035

Puertollano, E., Puertollano, M.A., Cruz-Chamorro, L., De Cienfuegos, G.Á., Ruiz-Bravo, A. and De Pablo, M.A. (2009). Effects of concentrated supernatants recovered from Lactobacillus plantarum on Escherichia coli growth and on the viability of a human promyelocytic cell line. Journal of Applied Microbiology, 106(4), 1194-1203. https:// doi.org/10.1111/j.1365-2672.2008.04086.x

Ranadheera, R.D.C.S., Baines, S.K. and Adams, M.C. (2010). Importance of food in probiotic efficacy. Food Research International, 43(1), 1-7. https:// doi.org/10.1016/j.foodres.2009.09.009

Riazi, A. and Ziar, H. (2012). Effect of honey and starter culture on growth, acidification, sensory properties and bifidobacteria cell counts in fermented skimmed milk. African Journal of Microbiology Research, 6 (3), 486-498.

Ricci, A., Cirlini, M., Calani, L., Bernini, V., Neviani, E., Del Rio, D. and Lazzi, C. (2019). In vitro metabolism of elderberry juice polyphenols by lactic acid bacteria. Food Chemistry, 276, 692-699. https:// doi.org/10.1016/j.foodchem.2018.10.046

Sanz, M.L., Polemis, N., Morales, V., Corzo, N., Drakoularakou, A., Gibson, G.R. and Rastall, R.A. (2005). In vitro investigation into the potential prebiotic activity of honey oligosaccharides. Journal of Agricultural and Food Chemistry, 53, 2914-2921. https://doi.org/10.1021/jf0500684

Slačanac, V., Hardi, J., Lučan, M., Kun, S., Havas, P. and Krstanović, V. (2011). Effect of honey addition on fermentation activity of Lactobacillus casei Lc-01 in cow's and goat's milk: A kinetic study. Acta Alimentaria, 40(2), 270-281. https:// 
doi.org/10.1556/AAlim.40.2011.2.11

Tarazona-Díaz, M.P., Martínez-Sánchez, A. and Aguayo, E. (2017). Preservation of Bioactive Compounds and Quality Parameters of Watermelon Juice Enriched with L-Citrulline through Short Thermal Treatment. Journal of Food Quality, 2017, 3283054. https:// doi.org/10.1155/2017/3283054

Tayo, B.A. and Akpeji, S. (2016). Probiotic viability, physicochemical and sensory properties of probiotic pineapple juice. Fermentation, 2(4), 20. https:// doi.org/10.3390/fermentation2040020

Thakur, M. (2017). Development of Probiotic Pomegranate Beverage and Its Physico-Chemical and Microbial Characterization. International Journal of Pure and Applied Bioscience, 5(1), 35-41. https://doi.org/10.18782/2320-7051.2488

Tournas, V.H., Heeres, J. and Burgess, L. (2006). Moulds and yeasts in fruit salads and fruit juices. Food Microbiology, 23(5), 684-688. https:// doi.org/10.1016/j.fm.2006.01.003

Tripathi, M.K. and Giri, S.K. (2014). Probiotic functional foods, Survival of probiotics during processing and storage. Journal of Functional Foods, 9, 225-241. https://doi.org/10.1016/ j.jff.2014.04.030

Vinderola, C.G. and Reinheimer, J.A. (2000). Enumeration of Lactobacillus casei in the presence of L. acidophilus, bifidobacteria and lactic starter bacteria in fermented dairy products. International Dairy Journal, 10(4), 271-275. https:// doi.org/10.1016/S0958-6946(00)00045-5

Vinderola, C.G., Prosello, W., Ghiberto, D. and Reinheimer, J.A. (2000). Viability of probiotic (Bifidobacterium, Lactobacillus acidophilus and Lactobacillus casei) and nonprobiotic microflora in Argentinian Fresco cheese. Journal of Dairy Science, 83, 1905-1911. https://doi.org/10.3168/ jds.S0022-0302(00)75065-X 